\title{
The Impact of Digitally Regulated Peer Corrective Feedback (CF) on Students' English Writing
}

\author{
Bambang Agus Darwanto*, Herman Dwi Surjono, Dyah Setyowati Ciptaningrum \\ School of Graduate Studies, Yogyakarta State University, Indonesia
}

Received July 21, 2020; Revised August 19, 2020; Accepted September 29, 2020

\section{Cite This Paper in the following Citation Styles}

(a): [1] Bambang Agus Darwanto, Herman Dwi Surjono, Dyah Setyowati Ciptaningrum , "The Impact of Digitally Regulated Peer Corrective Feedback (CF) on Students' English Writing," Universal Journal of Educational Research, Vol. 8, No. 11, pp. 5388 - 5394, 2020. DOI: 10.13189/ujer.2020.081141.

(b): Bambang Agus Darwanto, Herman Dwi Surjono, Dyah Setyowati Ciptaningrum (2020). The Impact of Digitally Regulated Peer Corrective Feedback (CF) on Students' English Writing. Universal Journal of Educational Research, 8(11), 5388 - 5394. DOI: 10.13189/ujer.2020.081141.

Copyright $@ 2020$ by authors, all rights reserved. Authors agree that this article remains permanently open access under the terms of the Creative Commons Attribution License 4.0 International License

\begin{abstract}
This qualitative research investigated if corrective feedback (CF) through a digitally regulated collective evaluation mechanism can generate appropriate revisions in the student's English essays regarding language components. The research used a self-developed learning management system (LMS). Students of an Academic Writing class participated in the study and were required to upload 5-paragraph essays to the LMS and participate in giving CF. The minimum words for every text and the minimum evaluators for each essay were set-up digitally. Learning artifacts of three students were randomly selected using an MS Excel formula and then content-analyzed for the CF of language aspects using NVivo12. The peer CF was then traced back in the final essay. Results show that most of the final revisions do not take on the $\mathrm{CF}$ from peers especially regarding the high-order feedback like content (idea), organization, and diction. However, such low-order feedback as typo, capitalization errors, subject-verb agreement, and preposition-noun agreement are identified in the revisions. In conclusion, not all peer-CFs were adopted and the low-order CF is found more pronounced than the high-order one. The finding suggests that online collective CF with a regulated mechanism to an extent can trigger editing skills especially when focused on the low-order errors.
\end{abstract}

Keywords Corrective Feedback (CF), High-order vs. Low-order CF, Language Components, Collective Evaluation

\section{Introduction}

The idea to develop a new learning management system (LMS) with e-portfolio functionalities was initially motivated by the fact that teacher-student single traffic paper correction was sometimes found uninteresting and less beneficial to both the students and the teacher. The students have to wait for long to get feedback from their teacher, which is usually given in prints with the teacher's marks here and there and they are composed of single-angle input to improve the students' knowledge and skills of English. Actually, the teacher can involve other students to push participation to promote language practice and to provide richer feedback. However, when carried out in prints this idea will be highly cumbersome. In the traditional assessment practice, correcting writing works is commonly done on paper and is carried out by the teacher only.

Then, some teachers at the school where this research was conducted tried to find LMSs to complement this weak point. They searched for a medium for collective evaluation practice. Some tried to use the Google Classroom and Schoology, and some others prefer using Moodle Cloud to mediate this idea. However, integrating a systemic continuous collective evaluation into the LMSs is not yet possible. They have not been equipped with a feature to enable all students in an across classes to get 
involved in providing CF and other suggestions to a project, one that all system inhabitants can view and give recorded comments or evaluation. The peer-evaluation receivers can improve their work in the self-evaluation page based on all the received evaluative words. For this reason, the new LMS was then developed.

Research about the impact of systemic and sustainable online collective CF via an asynchronous technology of an LMS is new. Asynchronous e-learning is a learner-centered learning approach that takes the advantage of computer-mediated communication (CMC) and employs online resources to provide information sharing not limited by time, place, and the constraints of the classroom [1]. Asynchronous e-learning emphasizes the importance of peer-to-peer interaction and can promote active-interactive discussions. However, the module for discussion in a LMS is usually provided in the form of "Question" and then the groups or the whole class members can give responses. Students cannot yet access and give evaluative comments to all posts by all students in the LMS system. In the discussion forum, the teacher's role is not yet clear whether $\mathrm{s} /$ he serves as an assessor (a rater) or simply another commenter.

In the new LMS for this study, students are given privileges to view their peers' posts of their interest and give feedback. Students by system or automatically have to comply with the systemically demanded activities otherwise, the collective completion of the posted project cannot be fulfilled. This is because the system dictates that one's negligence (poor collaborators) can risk every student's online processes that have been set-up digitally and it will risk the collective success.

\section{Theoretical Perspectives}

Evaluation of the student's works of English provided by the teacher and inside a classroom is necessary yet never sufficient. In the traditional learning model, the feedback is singly provided by the teacher whereas there should be other feedbacks that may also be worth considering. In addition to this, reciprocally, other students can ripe benefits from giving their views about their own learning evidence and others'. They can create output for new input both for himself and for other students. Students can be provided with chances to get evaluative-corrective feedback from the teacher himself and from peers and this idea is now made possible with the help of online technology.

The term feedback in this research is any reactions positive and negative towards students' learning evidence intended to provide responses for work or competence improvement provided directly or indirectly. And, feedback giving can be classified into its direct and indirectness [2], types of media (offline vs. online), involved parties (teachers, students, or both).

A growing body of studies shows the strategic values of corrective feedback to language learning and studies on corrective feedback (CF) have been found abundant. In the research, CF is usually mainly given by the class teacher as reported by [3], [2], [4], and [5].

There are also researches on the benefits of corrective feedback with peers as the feedback providers as reported by [6], [7], [8], [9], [10], and [11]. For instance, a study carried out by [12] found out that using technology and the internet in teaching writing could increase students' participation and collaboration. Also, [13] similarly wrote that peer feedback encourages students to hold one another of the work and to see each other as collaborators. Furthermore, [9] noted that peer feedback has proven to be an effective means of aiding writing development since it actively involves learners in the learning and teaching process. In all these studies, however, CF is not yet systemically pushed. In addition to this, it has not been clear yet what the teacher did when students were not interested in joining the CF activity.

Furthermore, in the aforementioned works, the tech-based peer CF mechanism that can incorporate students of intra-class and inter-class within a LMS to collectively provide CF to a learning evidence needs to be explored. The idea of collective evaluation mechanism has been made possible with the advent of online teaching-learning technology, and this tech-aided process of teaching and learning can be facilitated with a learning management system (LMS) to serve as a virtual ecology for evaluative interactions. By collective evaluation, it is a process of feedback-giving by not only the class members but also by the other students (and teachers) of other classes so long as they are all registered in one technological ecology or one collectively-shared LMS. This should be highly probable by integrating the functionalities of an e-portfolio into a LMS.

According to [14], a digital LMS is of two kinds: synchronous LMS and asynchronous LMS. The latter is intended to support the learning activities such as the provision of learning materials, a discussion forum, tests, and assignments, and the assignment features are the common features among the LMSs; however, such straightforward functionalities as those offered by an e-portfolio are not yet found in them. A module that allows the system's members including students and teachers within one class and across classes to evaluate a student's project is not yet commonly found. Many LMSs do not yet give the privilege to all students in the class let alone in other classes to view a work and to give feedback to the work.

As for this new e-portfolio LMS, first, it is built on the web platform to ease up access and operation and can allow all artifacts to be shared within the LMS both in and across classes. Second, this LMS architecture enables all system inhabitants to communicate in every interactional phase, from the project submission (upload) to the scoring phase in one evaluative cycle as illustrated below. 


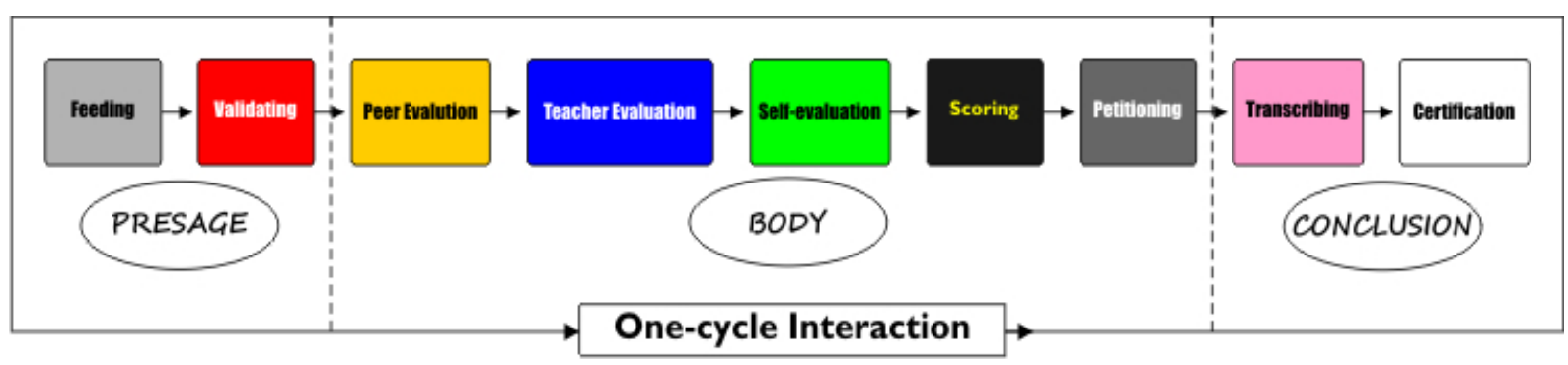

Figure 1. One-cycle Collective CF Mechanism

The interaction process starts with the initial (presage) learning phase that is composed of feeding the system and validating the upload. In the body of the process, students and teachers are involved in rich interactions by giving comments, evaluation, self-reflection, and extending score petition. As for the conclusion phase, students can print both their transcript containing the titles along with their scores and the certificate of all cycles completion. The LMS allows other classes to participate in the internet-mediated communication (IMC). When one class runs, other students and teachers in other classes who have been registered in the system and interested in the upload (texts, videos, images, and audios) can read, view, watch, and give evaluative comments to the project. This way, the presence of readers or viewers, and even evaluators of a project, an artifact, or learning evidence can be guaranteed.

In the system, the artifact of English use must receive evaluations from the teacher, peers, and the student himself. If a project has received a minimum number of evaluators, project evaluation completion can be guaranteed. The LMS can also admit videos, audios, or images. It can accommodate all kinds of media formats. Students can choose any uploads of his preference to evaluate. Collective evaluation can be given to any artifacts of any of these formats.

To maximize language interaction, this LMS carries a hold-system mechanism through which students and the teacher are systemically pushed to give feedbacks/comments/evaluations to the uploaded project. This mechanism helps push teachers to be responsive to students' uploads. This hold-system mechanism dictates or preconditions that the required activity is met by each corresponding system's member so that one project can be released to reach the scoring phase. Ignoring the required responses can end-up in project holding. It will be held immovable until the necessary reaction is provided. In this way, the presence of evaluators is guaranteed. This mechanism can ensure that every project is viewed (watched), read, listened, commented, and evaluated. With this mechanism, language production, online interactions, and collaborations can be promoted.

This mechanism uses numerical settings and the project progress is notified using colors. The colors are to indicate the current interactional movement of an artifact. Different colors (grey, red, yellow, blue, green, black, and pink) call different activities by different system inhabitants. Through the colors, the teacher, the peers, and the students are pushed to provide the demanded action. Each of the colors appears on each of the progress pages of the online interaction with one's upload serving as an object of the discussions. By looking at the colors, the lecturer in charge (LiC)/teacher and the students and peers can always monitor up to which stage their project has been processing including whether it has been appropriately peer-evaluated.

Students are involved in the online CF in cyclical steps. Each step requires different activities depending on the learning evidence that the students have fed into the system. The types of corrective feedback to texts can be different from that of a video, audio, or images.

Corrective feedback is also known as peer feedback, peer review, or peer evaluation. [9] noted that it can effectively help aid writing development because it involves learners in the teaching and learning process in the classroom. They continued that CF can also enhance learner autonomy, cooperation, interaction, learning responsibility, and collaboration and these benefits can be promoted by using e-portfolio learning mechanism.

E-portfolio-based learning design has proven to bring various benefits to teaching and learning as reported in [15] and since digital portfolio brings various benefits Cram et al. [16] suggest the integration of e-portfolio into a curriculum. This is to upload, organize, store, showcase, provide chances for feedback from peers and teachers to improve the 'product' quality.

Research by [17] investigated assessment through an e-portfolio. The study investigated the impact of e-portfolio assessment on students' writing performance. The experimental group was given a treatment of e-portfolio assessment, while the control group was given traditional methods of teaching and assessing students' writing. After logging into the Telegram app, the students in the experimental group wrote up each of the assignments in a single post. Other students and the teacher put comments and gave error correction. The results showed that the experimental group outperformed the control group and it proves that e-portfolio assessment can develop students' writing skills and can raise learning motivation. In this research, however, collective error correction in the assessment process has not been illustrated as to which correction was actually accepted and reflected in the final 
document. Are all the corrective feedbacks worth considering by the student? This is because students do not commonly consider their peer's comments as worth attending compared to their teacher's feedback let alone when the teacher's comments and correction are given simultaneously with the comments from the students, for this can be pre-empting or priming similar responses from his students themselves.

CF can be very straightforward attending simple, factual, and readily detected errors in linguistic aspects such as capitalization of an initial word of a sentence, spelling, verbal-nominal distinction, passive-active cases, and other similar errors. The feedback is highly uncomplicated to process and in this sense, it belongs a low-order CF. Some $\mathrm{CF}$ can be too vague to pinpoint to follow such as, "Your writing needs improvement". This type of CF belongs to high order feedback that is hard to take on.

\section{Research Questions}

This study was to find out answers to the following research question:

- Do CF receivers take on their peers' CF into the final essay?

\section{Research Method}

\section{A. Participants}

Sixteen students of an Academic Writing class participated in the study. These students were those in their second-to-final semester, which means that they were already holding a TOEFL prediction score of min 475 as required by the English department as a prerequisite to register in the semester.

\section{B. The procedures}

The students were required to construct 5-paragraph argumentative writing of any topic of their interests. This strategy of topic selection should avoid learning apprehension since they were writing something they are interested in and familiar with. This should lessen students' anxiety.

After being uploaded (published) into the LMS, the essay was readily viewable by all LMS inhabitants including those in other classes yet still within the system. Students may click "My Class" or "All Classes" to view any topic of interest. As for the guidance for writing, it was presented as pop-up help. When they were writing, it would be dropping down on the screen and remain there until the student closed the help box. When uploads and peer CF were completed, the artifacts that they had made were automatically stored to be then downloaded for a further analysis. Students gave CF to any topic of their interest.

Out of the 16 participants, 3 students' artifacts were selected randomly to be content-analyzed. The random selection was conducted using the formula of the MS Excel: $=\operatorname{INDEX}(\$ A$ \$2:\$A $\$ 18$, RANDBETWEEN $(1$, COUNTA $(\$$ $A \$ 2: \$ A \$ 18)), 1)$. When applied to the list of the students, this formula would give one name for each click and the process was repeated 3 times to get 3 students.

\section{The analysis}

The text data were downloaded from the interlanguage corpus storage in the LMS and the datasets were composed of (1) the original drafts, (2) the validation comment by the teacher, (3) the CF from peers (peer-evaluation data), (4) the CF from the teacher, and (5) the revised essays.

This research looked at only three different datasets: original essays, CF from peers, and final essays. The dataset of the CF was content-analyzed through the coding process using NVivo12. The codes were of the five language aspects by [18] of (1) content, (2) language use, (3) organization, (4) mechanics, and (5) vocabulary as presented below.

Table 1. Areas of Corrective Feedbacks

\begin{tabular}{|c|c|c|}
\hline No. & Aspects & Focus of the Aspects \\
\hline 1 & Content & Relevance to topic and topic development \\
\hline 2 & Organization & Logical sequencing, coherence, cohesion \\
\hline 3 & Vocabulary & $\begin{array}{l}\text { Range of words and idioms and the } \\
\text { appropriateness }\end{array}$ \\
\hline 4 & $\begin{array}{l}\text { Language } \\
\text { use }\end{array}$ & $\begin{array}{l}\text { Agreement, tense, number, word order, } \\
\text { articles, pronouns, prepositions, run-ons, } \\
\text { and fragments, etc. }\end{array}$ \\
\hline 5 & Mechanics & $\begin{array}{l}\text { Capitalization, punctuation, spelling, } \\
\text { paragraphing, etc. }\end{array}$ \\
\hline
\end{tabular}

The CF datasets were coded according to the 5 areas by [19] and the results were then traced in the final essay to find out if proofs of relevant corrective input were attested. But before being traced, the initial draft and the final work were compared for a text similarity test using the CopyLeaks application. This was to ensure that there were differences detected in the two texts, otherwise a further process of analysis on the particular text would not be undertaken. When differences were found, tracing over the CF of the 5 English language aspects as given by the peers in the final text were continued. This was to prove if the CF was taken on.

\section{The Findings}

All students submitted the required 5-paragraph argumentative essays into the system and all had undergone the grammar and plagiarism check as required by the LMS procedures. Furthermore, their works were already validated (by the teacher) for sensitive wordings containing racism, inter-religion issues, and obscenity.

The main content (ideas) of each essay had also been fully supplied in the narration box (numerically regulated) that must be completed along with an uploaded essay to 
make it viable for the next project processes. The next process was the peer evaluative feedback phase. The number of evaluators was set to 6 for the minimum before the project can move to the next phase (the teacher evaluation). The peers (and the student himself) and the teacher can provide feedback here as well. A discussion about the uploaded essay took place on this page.

The analysis using the CopyLeaks application indicates that the original work and the final revision were found different regardless the level, which means that efforts for improving their essays were detected. Revisions were found but not yet clear if they accommodated the CFs from peers.

The next analysis with NVivo12 was then carried out and results showed the feedback regarding the 5 linguistic aspects. Some entries proved not to carry CF. Entries without CF are exemplified as follows (copied as is).

1. Thank you Mary, you have given me new information about planting.

2. I learn about cutting corner from you essay.

3. Very good. Keep up the good work.

While entries with CF are as follows (copied as is).

1. (Organization) - And then, if there is any sources or references, you can put it at the end session of your writing.

2. (Mechanics) - I think you should revise your writing format on your title, because you have used small letter, except the first letter

3. (Grammar) - From the grammatical, you could change the article on the words 'an cheerful song' into 'a cheerful

4. (Content) - Then in the third paragraph, I think you could explain it more.

5. (Vocabulary) - In my opinion, the word 'is' can replace in to 'has' or you can change 'reason' in to 'reasoning'.

Data shows that not all students were similarly enthusiastic about the online activities as seen in the number of entries. It ranges from 5 to 96 and not all entries carry CF. It is also accounted that those who wrote more entries gave a bigger percentage of CF. For instance, N1 gave $83 \%$ CF of all his entries and N16 gave only 1 CF out of his 5 entries (20\%).

This class made 45 pages of CF entries. When classified into the 5 linguistic aspects by [18], the amount of CF of each of the 5 areas is as follows.

Table 2. Rates of CF by Language Components

\begin{tabular}{|c|c|c|c|}
\hline No & Nodes & & CF of All Entries \\
\hline 1 & Content & & $34 \%$ \\
\hline 2 & Language Use/grammar & & $28 \%$ \\
\hline 3 & Mechanics & & $19 \%$ \\
\hline 4 & Organization & & $10 \%$ \\
\hline 5 & Vocabulary & & $9.7 \%$ \\
\hline \multicolumn{3}{|c|}{ TOTAL CF } & $100 \%$ \\
\hline
\end{tabular}

Data indicates feedback about contents (high order feedback) is the most pronounced (34\%). The students seem to be also confident to give feedback about grammar/language use (28\%). On the contrary, they are not quite interested in giving CF on the essay organization and vocabulary use (e.g. word choice).

Next, we will look at the data if the peer CFs were taken on by the students as reflected in the final texts. Below are one initial text, the $\mathrm{CF}$, and its final revision.

Data indicates that high order CF like feedback to content and organization is hardly taken on. Conversely, even though not found pervasive, corrections on low order $\mathrm{CF}$ are detected. The common areas of correction are as follows.

1. subject-verb (S-V) agreement,

2. capitalized words,

3. the use of period in a sentence,

4. "be" overuse

5. missing "to" (for "to + infinitive")

6. preposition + noun (verb +ing/gerund)

These areas were the most frequently attended by the CF receivers. The CF on the diction domain was left neglected.

\section{Discussion}

Data shows that not all students create the same number of entries and not all the entries carry CF. This is because some students may not have felt secure to give CF to their peers. They might feel that their current language competence has not been ready to venture into giving CF to their classmates. Despite so many previous research findings indicating the advantages of employing peer correction in the teaching of writing as reported by [9], [20], [3], data indicates that not all students are similarly willing or confident to provide corrective entries to their peers. As a result, they would go around $\mathrm{CF}$ that does not really give clear ways to solve the errors in their friends' works. It is possible that these CF providers have knowledge about the error areas. Even so, they might not have enough courage to 'criticize' their friends' works for unknown reasons yet.

These students are more interested or more confident in giving indirect CFs than direct CFs and this is the reason why they are interested in giving feedback to content and organization. The two areas are high order CFs that the feedback receivers may not want to use because the CF is less mathematical as opposed to such CFs on subject-verb agreement and verbal-nominal issues that are rule-based and not ambiguous. For the CF providers, it is safer to provide indecisive $\mathrm{CF}$ that the preciseness can still be argued rather than providing direct $\mathrm{CF}$ that the correctness can be directly debated.

Further reasons for not providing direct CF can be assumed, however. As already slightly mentioned above, that students do not venture into giving direct CFs can be because they are not sure if their feedback is worth giving 
and they might not be confident enough with their own English competence. Direct CFs around high order cases are avoided. They may feel that they are not ready to give open/public feedback to their peers that all system inhabitants can view/read. The sample CFs below are copied as is.

1. Then in the third paragraph, I think you could explain it more.

2. I think you need to be more thorough with your work

3. It is also better to use more data in explaining your reasons and put the references below. Good job.

4. But, clarify the topic in each paragraph so that it will be more easy to understand.

These high order CFs are not readily taken on. It is harder than correcting such errors in *He is come from Jakarta, *Mary always happy, or *i was there at that time as found in the texts and it is accounted in the data.

Conversely, the CF providers seem to be highly confident when they give direct low-order feedback as exemplified below (copied as is).

1. From the grammatical, you could change the article on the words 'an cheerful song' into 'a cheerful song'.

2. In my opinion, the word 'is' can replace in to 'has' or you can change 'reason' in to 'reasoning'.

3. But, I found some grammatical errors such as "it is do not", you may revise it into "it does not".

These sample cases indicate that the students would confidently provide feedback to simple and straightforward grammatical errors, but not really to those that may bring contra-feedback to them.

That the CF receivers do not fully comply with the CF given by their peers suggests several issues. First, these students do not really trust the CF given by peers especially regarding the errors that pertain to complicated grammatical issues. Probably, they are not quite sure that the CF is worth attending.

Second, they might think that the CF is just too extensive coming from so many parties that they can hardly discern and follow all of them at all. Besides, there is also CF given by the teacher(s). They might want to take on the CF from the teacher, instead. However, this still needs to be explored in the next study since this paper does not take that issue into this research.

\section{Conclusions}

This research has revealed several findings regarding the benefits of numerically regulated collective CF for writing works. First, the mechanism of numerical setting in the LMS has managed to push all students to participate in the online communication (interaction) and English production. All students by system have complied to the digital settings in the LMS. All students ventured into creating a project, uploading it, and providing CF to their peers' works. Second, the online collaboration to attain mutual success proves to work effectively. No students refrain from giving CF because ignoring it can result in 'retaliation'. Other students may not want to give reciprocal CF either and this will cause project jam. One project will stay in one page or immovable and cannot reach the final step of project recognition system. Third, $\mathrm{CF}$ receivers even though not following all the CF given, prove to take on some of the CF especially one that provides clear-cut solution not those that do not provide straightforward way outs. In conclusion, the collective evaluation mechanism in the LMS by intra and inter-class students prove to be effective to raise language production and internet mediated communication (IMC). The pushed CF mechanism in the LMS increases the amount language output and can brush up students' analytical skills regarding the 5 linguistic areas as explored in this study.

\section{REFERENCES}

[1] M. M. Shahabadi and M. Uplane, "Synchronous and asynchronous e-learning styles and academic performance of e-learners,” Proceida, Soc. Behav. Sci., vol. 176, pp. 129138, 2015.

[2] E. Eslami, "The effects of direct and indirect corrective feedback techniques on EFL students' writing," Procedia Soc. Behav. Sci., vol. 98, pp. 445-452, 2014.

[3] S. Tangkiengsirisin and R. Kalra, "The effect of corrective Feedback on grammatical accuracy in a Thai University context,” Asian EFL J., vol. 20, no. 7, pp. 228-233, 2018.

[4] D. Ferreira, "Written corrective feedback and peer review in the BYOD classroom,” EUROCALL, no. 2013, pp. 86-92, 2013.

[5] B. Jabu, N. Noni, A. Talib, and A. Syam, "Lecturers' use of corrective feedback and students' uptake in an Indonesian EFL context,” vol. 19, no. 1, pp. 82-87, 2017.

[6] M. J. Itmeizeh, "Impact of peer correction on reducing English language students' mistakes in their written essays in PAUC and learners' attitudes towards this technique," Theory Pract. Lang. Stud., vol. 6, no. 11, pp. 2068-2078, 2016.

[7] J. P. Lantolf and S. L. Thorne, Sociocultural theory and the genesis of second language development. Oxford: Oxford University Press., 2006.

[8] O. Birgin and A. Baki, "The use of portfolio to assess student' s performance,” J. Turkish Sci. Educ., vol. 4, no. 2, pp. 7590, 2007.

[9] I. R. Balderas, P. María, and G. Cuamatzi, "Self and peer correction to improve college students' writing skills," Profile, vol. 20, no. 2, pp. 179-194, 2018.

[10] S. E. K. Otto, “Toward langua - technocultural competence,” in The handbook of technology and second language teaching and learning, C. A. Chapelle and S. Sauro, Eds. 
9600 Garsington Road, Oxford, OX4 2DQ, UK: Wiley-Blackwell, 2017, pp. 10-25.

[11] B. Bram, “Self and peer revisions in students' narrative paragraph writing," Asian EFL J., vol. 20, no. 8, pp. 232237, 2018.

[12] I. M. Rajeg and I. B. P. Yadnya, “TEFLIN CONFERENCE 2014 -Book 3,” in English Language Curriculum Development: Implications for Innovations in Language Policy and Planning, Pedagogical Practices, and Teacher Professional Development, 2014, pp. 946-950.

[13] M. Hismanoglu et al., "The influence of formal language learning environment on vocabulary learning strategies," $J$. Lang. Teach. Res., vol. 3, no. 1, pp. 23-29, 2012.

[14] Y. Wang and N. Chen, "Criteria for evaluating synchronous learning management systems : arguments from the distance language classroom,” Comput. Assist. Lang. Learn., vol. 22, no. 1, pp. 1-18, 2009.

[15] C. R. Kilbane and N. B. Milman, "Examining the impact of the creation of digital portfolios by high school teachers and their students on teaching and learning," Int. J. ePortfolio vol. 7, no. 1, pp. 101-109, 2017.

[16] M. McNeill and A. Cram, "Evaluating e-portfolios for university learning: Challenges and opportunities," Chang. Demands, Chang. Dir. Proc. ASCILITE, no. January 2011, pp. 862-873, 2011.

[17] M. R. Khodashenas and F. Rakhshi, "The effect of electronic portfolio assessment on the writing performance of Iranian EFL learners,” Int. J. Res. English Educ., vol. 2, no. 3, pp. 67-77, 2017

[18] H. L. Jacobs, S. A. Zinkgraf, D. R. Wormouth, V. F. Hartfiel, and J. B. Hughey, Testing ESL composition: A practical approach. Rowley, M.A.: Newbury House of Publsihers, Inc., 1981.

[19] B. Ghanbari, H. Barati, and A. Moinzadeh, "Rating scales revisited: EFL writing assessment context of Iran under scrutiny,” Lang. Test. Asia, vol. 2, no. 1, pp. 83-100, 2012.

[20] C. A. Chapelle and S. Sauro, The handbook of technology and second language teaching and learning. 2017. 